\title{
Efficacy of Fluorine-18-Deoxyglucose Positron Emission Tomography in Detecting Tumor Recurrence After Local Ablative Therapy for Liver Metastases: A Prospective Study
}

\author{
By B.S. Langenhoff, W.J.G. Oyen, G.J. Jager, S.P. Strijk, Th. Wobbes, F.H.M. Corstens, and T.J.M. Ruers
}

\begin{abstract}
Purpose: The aims of this prospective study were to investigate the potential role of fluorine-18-deoxyglucose (FDG) positron emission tomography (PET) in determining the efficacy of the local tumor ablative process and to determine the added value of FDG-PET in the detection of tumor recurrence during follow-up.

Patients and Methods: Twenty-three patients with unresectable colorectal liver metastases were followed up after local ablative therapy consisting of a standard protocol including FDG-PET scanning, computed tomography (CT) scanning, and carcinoembryonic antigen measurements. The mean follow-up period was 16 months (range, 10 to 21 months).

Results: Ninety-six lesions was treated, 56 by local ablative treatment. Within 3 weeks after local ablative treatment, 51 lesions became photopenic on FDG-PET, while five lesions (in five patients) showed persistent activity on FDGPET. In four of five FDG-PET-positive lesions, a local recurrence developed during follow-up; one FDG-PET-positive lesion turned out to be an abscess. None of the FDG-PET-
\end{abstract}

$S^{\prime}$ URGICAL RESECTION is the treatment of choice in patients with colorectal liver metastases. The 5-year survival rate after resection of colorectal liver metastases ranges between $25 \%$ and $40 \%$, with a median survival time between 28 and 46 months. ${ }^{1-6}$ Recently, local ablative techniques such as cryosurgery ablation (CSA) and radiofrequency ablation (RFA) have received considerable attention for the treatment of colorectal liver metastases. ${ }^{7-11}$ Until now, these techniques have mainly been used as adjuncts to hepatic resection in patients in whom complete tumor clearance of the liver cannot be obtained by resection alone. CSA and RFA are performed during intraoperative ultrasound monitoring in order to assure complete tumor treatment. During CSA, an "ice ball" is formed that leads to a hypoechogenic area which should include all tumor tissue. During RFA, air bubbles seen in the treated lesion create a hyperechogenic area. ${ }^{12,13}$ Despite improvements, the extensive use of local ablative techniques is still hampered by limitations in monitoring of the destruction process at the time of treatment. The frequency of incomplete treatment and hence local recurrence after local ablation is relatively high. After CSA, local recurrence at the cryosite is observed in $2 \%^{14}$ to $44 \%{ }^{15}$ of patients. For RFA, these figures (lesion-based analysis) range between $2 \%$ and $55 \% .^{16}$

After local ablative therapy, local recurrence and hence treatment failures are, unless at a late stage, not easily identified with anatomic imaging modalities such as computed tomography (CT) scans and ultrasound. With these techniques, normal postablative treatment effects can hardly be differentiated from residual tumor or recurrent disease. ${ }^{12}$ More accurate imaging modalities evaluating the treatment efficacy of local tumor ablation will not only improve the evaluation of these new ablative techniques in liver surgery but also offer the opportunity negative lesions developed a local recurrence during a mean follow-up period of 16 months. During follow-up, 11 patients showed recurrence in the liver outside of the treated area. In all cases, previously negative FDG-PET scans became positive. Extrahepatic recurrence was encountered in nine patients during follow-up; FDG-PET showed all nine cases of tumor recurrence. There was one false-positive FDG-PET caused by an intra-abdominal abscess. In all patients, the time point of detection of recurrence by FDG-PET was considerably earlier than the detection by CT.

Conclusion: FDG-PET seems to have a significant impact in measuring treatment efficacy directly after local ablative therapy. Furthermore, FDG-PET has an added value in patient follow-up because it reveals recurrences earlier than conventional diagnostic modalities.

J Clin Oncol 20:4453-4458. (-) 2002 by American Society of Clinical Oncology.

for early reintervention by either surgery or repeated local ablation in case of an insufficient initial treatment result. Positron emission tomography (PET) with fluorine-18-deoxyglucose (FDG) is an imaging modality that allows direct evaluation of cellular glucose metabolism. Being a functional imaging modality, FDG-PET may be of added value in differentiating between residual tumor, recurrent disease, and postoperative treatment effects. In this study, we investigated (1) the potential role of FDG-PET in measuring the efficacy of local tumor ablation as well as (2) the added value of FDG-PET in the detection of tumor recurrence during follow-up.

\section{PATIENTS AND METHODS}

\section{Patient Population}

Between April 1998 and July 2000, 23 patients with unresectable colorectal liver metastases were treated using local tumor ablation by means of CSA or RFA. Local ablation was considered when patients met the following criteria: (1) metastases confined to the liver and judged unresectable due to technical considerations related to location or extent of the disease; (2) number of metastatic deposits was 10 or less; and (3) local tumor ablation alone or in combination with resection allowed complete eradication of tumor from the liver. In all patients, the preoperative work-up consisted of a CT scan of the abdomen and chest, a whole-body FDG-PET scan, a barium

From the Departments of Surgery, Nuclear Medicine, and Radiology, University Medical Center Nijmegen, Nijmegen, the Netherlands.

Submitted December 28, 2001; accepted July 25, 2002.

Address reprint requests to T.J.M. Ruers, MD, Department of Surgery, University Medical Center Nijmegen, P.O. Box 9101, 6500 HB Nijmegen, the Netherlands; email: T.Ruers@heel.azn.nl.

(C) 2002 by American Society of Clinical Oncology.

0732-183X/02/2022-4453/\$20.00 
enema of the colon or coloscopy, and serum carcinoembryonic antigen (CEA) measurements. No postoperative adjuvant chemotherapy was given.

\section{Operative Technique}

Surgery was performed through an extended right subcostal incision. The abdominal cavity was thoroughly explored to exclude extrahepatic disease. Biopsy specimens and fresh frozen sections were taken in case of suspicious lymph nodes or peritoneal deposits. The liver was mobilized from its ligamentous attachments, and the extent of the disease was mapped by careful palpation and intraoperative ultrasound. The number of lesions and their relationships to the major biliary and vascular structures were determined, and final resectability was assessed. Large tumor size and locoregional invasion of perihepatic structures such as the diaphragm were not considered a contraindication to operation as long as resection could clear all tumor tissue. During all surgical procedures, resection was considered to be the treatment of choice. When complete resection could not be achieved, the decision was made either to perform CSA or RFA alone or to combine resection of the resectable lesions with local ablative therapy of unresectable deposits. ${ }^{17}$ In general, CSA was used during the early period of the study, and RFA was used during the last 10 months of the study when this technique became available in our clinic.

\section{Technique Hepatic Cryosurgery}

After localization of the liver metastases, a cryoprobe (LCS 2000; Spembly Medical, Hampshire, United Kingdom) was introduced under ultrasound guidance into the center of the tumor. During introduction, major vascular and biliary structures were avoided. After accurate positioning of one or more cryoprobe(s), liquid nitrogen was driven through the probe at $-196^{\circ} \mathrm{C}$. During the freezing process, continuous ultrasound monitoring of the lesion was carried out to ensure that the ice ball, visible as a hypoechogenic area around the tip of the cryoprobe, exceeded the diameter of the lesion by approximately $1 \mathrm{~cm}$. Two freeze-thaw cycles per lesion were performed. Inflow occlusion (the Pringle maneuver) was sometimes used to increase the efficacy of the freezing process. In general, separate lesions were frozen sequentially rather than simultaneously. After completion of the freezing procedure, cryoprobes were removed and the probe entry site was filled with fibrin sealant (Tissucol; Baxter, Utrecht, the Netherlands).

\section{Hepatic Radiofrequency Technique}

For RFA, the Cool-tip system (Radionics; Tyco Healthcare Group LP, Burlington, MA) was used. Under ultrasound guidance, the cooled-tip electrode was placed in the center of the tumor. For lesions smaller than $3 \mathrm{~cm}$ in diameter, a single cooled-tip electrode was used; for lesions larger than 3 $\mathrm{cm}$, RFA was performed with a cooled-tip cluster electrode. For lesions larger than $4 \mathrm{~cm}$, tumor ablation was achieved by several probe insertions. RFA is based on alternating current through the tissue, thereby creating friction on a molecular level. This results in increased intracellular temperature and localized interstitial heating. During the heating process, air bubbles arise around the tip of the electrode, which creates a hyperechogenic area around the probe. In RFA, not only should the tumor be necrotized but also a 0.5 - to $1.0-\mathrm{cm}$ thick rim (ie, a surgical safety margin) of peritumoral liver tissue should be treated in order to destroy infiltrating tumor and reduce the risk of recurrence. ${ }^{18}$

\section{Imaging}

FDG-PET scanning. A dedicated, rotating, half-ring FDG-PET scanner (ECAT-ART; Siemens/CTI, Knoxville, TN) was used for data acquisition. Before injection of FDG, patients fasted for at least 6 hours. Intake of sugar-free liquids was permitted. Immediately before the procedure, the patients were hydrated with $500 \mathrm{~mL}$ of water. One hour after intravenous injection of 200 to $220 \mathrm{MBq}$ of FDG (Mallinckrodt Medical, Petten, the Netherlands) and $20 \mathrm{mg}$ of furosemide, emission images or emission and transmission images were acquired of the area between the proximal femora and the base of the skull (10 minutes per bed position). When only an emission study was recorded, the images were not corrected for attenuation and reconstructed using filtered backprojection (Butterworth filter with a cutoff frequency of 0.4 Nyquist). When emission and transmission studies were recorded, the images were corrected for attenuation and reconstructed using the ordered subsets expectation maximization algorithm. Recon- structed images were displayed in coronal, transverse, and sagittal planes. FDG-PET scans were evaluated by at least two nuclear physicians.

FDG-PET scans obtained immediately after local tumor ablation were scored for the presence or absence of residual FDG activity. After successful CSA or RFA, a photopenic area was seen on FDG-PET scans. Areas of focal FDG accumulation greater than background activity were interpreted as being pathologic.

CT scanning. CT examinations of the abdomen and chest were performed with a spiral CT scanner Somatom Volume Zoom; Siemens, Erlangen, Germany). All patients received diluted ionic oral contrast 1 hour before the CT examination. The liver was scanned before and after intravenous contrast injection. By use of an Envision CT injector (Medrad, Pittsburgh, PA) at a rate of $4 \mathrm{~mL} / \mathrm{sec}$, intravenous contrast material was injected through an 18-gauge catheter placed in an antecubital vein. A total of $100 \mathrm{~mL}$ of iohexol nonionic contrast material (Omnipaque, iodine 350 $\mathrm{mg} / \mathrm{mL}$; Nycomed, Princeton, NJ) was injected. The liver was scanned in the venous phase, 70 seconds after start of the injection. Both unenhanced and enhanced helical sequences were performed at $120 \mathrm{kV}$ and 15 to $300 \mathrm{mAS}$. Contiguous reconstructed sections (pitch 1:1) were obtained with 7-mm collimination. All examination results were stored on an optical disk for further review. In addition, hard copies of the scans were obtained for both series.

Each hard copy was analyzed separately by two independent reviewers (G.J., S.P.S.). Consensus was obtained in all cases. Second scans were read with knowledge of the first scans (reference scans). A sharply demarcated, hypoattenuated, nonenhanced area, which decreases in size on follow-up scans, was interpreted to mean there was no residue. An enhanced hyperemic rim around the margin of the ablated tissue was considered ablation-induced hyperemia. A faint, irregular, hypoattenuated area around the margins of the ablated tumor that increased in size on follow-up scans was interpreted as residual tumor.

\section{Postablation Analysis and Follow-Up}

Within 3 weeks after local ablative treatment, FDG-PET, spiral abdominal $\mathrm{CT}$, and serum CEA measurements were performed. To determine treatment efficacy, the postoperative and preoperative measurements were compared. The results of these immediately postoperative investigations became the reference for further follow-up investigations. After these initial investigations, standard follow-up consisted of FDG-PET, spiral abdominal CT, spiral chest $\mathrm{CT}$, and serum CEA measurements at 6 weeks after treatment and every 3 months thereafter.

\section{Data Analysis}

CT and FDG-PET images were evaluated by an independent investigator blinded to the results of CEA measurements. For every region, the concordance between CT and FDG-PET findings was verified. In case of a discordance, the FDG-PET findings were compared with the true lesion status, obtained by histopathologic confirmation $(n=1)$ and/or clinical follow-up by repeated imaging at least 9 months after the discordant observation. All recurrences showed a clear tendency to be enhanced on CT and FDG-PET scans. Discordant findings were subsequently classified as a true-positive, false-positive, true-negative, or false-negative. The mean follow-up period in this prospective study was 16 months (range, 10 to 21 months).

\section{RESULTS}

\section{Patients and Treatment Characteristics}

Seventeen patients were treated by CSA and six patients by RFA (Table 1). Sixteen of the 23 patients had synchronous metastases, and seven showed metachronous metastases. The number of liver lesions per patient varied from one to 10 . In all patients treated by $\mathrm{CSA},{ }^{17}$ local tumor ablation of unresectable lesions was performed in combination with hepatic resection of resectable tumor deposits. Of the six patients who underwent RFA, two patients were treated with both RFA and hepatic resection; the other four patients were treated by RFA alone.

The number of nodules treated by CSA and RFA ranged from one to seven, with a median number of 2.1 lesions for CSA and 3.5 lesions for RFA. The size of the metastases treated by CSA
Nijmegen on December 12, 2019 from 131.174.248.154 
Table 1. Treatment Characteristics

\begin{tabular}{lcc}
\hline & CSA & RFA \\
\hline No. of patients & 17 & 6 \\
Male/female & $11 / 6$ & $4 / 2$ \\
Age, years & & \\
$\quad$ Mean & 63.7 & 62 \\
$\quad$ Range & $51-78$ & $53-72$ \\
Total no. of treated lesions & & \\
$\quad$ Mean & 4.1 & 4.3 \\
$\quad$ Range & $1-10$ & $1-10$ \\
No. of lesions treated with local ablative therapy & & \\
$\quad$ Mean & 2.1 & 3.5 \\
$\quad$ Range & $1-7$ & $1-7$ \\
Diameter of lesions treated with local ablative therapy, cm & & \\
$\quad$ Mean & 2.6 & 2.4 \\
$\quad$ Range & $1-8$ & $1-6$ \\
With/without additional resection & $17 / 0$ & $2 / 4$ \\
\hline
\end{tabular}

varied from $1 \mathrm{~cm}$ to $8 \mathrm{~cm}$, and for RFA, from $1 \mathrm{~cm}$ to $6 \mathrm{~cm}$. All patients completed follow-up according to the protocol; there was no postoperative mortality. However, in one patient, the first postoperative FDG-PET scan was canceled due to clear abscess formation in the liver area. The mean follow-up period for patients was 16 months (range, 10 to 21 months).

\section{Immediately Postoperative Imaging}

Patient-based posttreatment analysis. In all 23 patients, CT scans taken within 3 weeks after local ablative therapy showed hypodense treatment areas without any evidence of tumor remnants. Air in the ablated lesions was seen on the initial CT scan in most cases. An abscess was found in one patient treated with CSA. In a second patient treated with RFA, initial CT findings were not specific (enhanced rim and presence of air) while an abscess developed several weeks after treatment.

Directly after local ablative therapy ( $<3$ weeks), FDG-PET was performed for 22 patients. In the patient with an abscess
Table 2. Patient-Based Analysis of FDG-PET Immediately After Local Tumor Ablation

\begin{tabular}{lcc}
\hline & CSA $^{*}$ & RFA \\
\hline No. of patients with positive FDG-PET before treatment & 17 & 6 \\
No. of patients with negative FDG-PET after treatment & 13 & 4 \\
No. of patients with positive FDG-PET after treatment & 3 & $2 \dagger$ \\
No. of patients who developed local recurrence at & 3 & 1
\end{tabular}

ablated site during follow-up

*One patient did not have the early postoperative FDG-PET due to an abscess. tOne patient had an abscess.

diagnosed shortly after CSA, FDG-PET scanning was not performed. In 17 of these 22 patients, the FDG-PET results became negative after treatment (Table 2). In five patients, FDG-PET scans remained positive (Fig 1). Three of these five patients had been treated with CSA and two with RFA. In these patients, FDG-PET scans showed focally increased activity at the edge of the treated lesions. Four of these five patients developed a local recurrence at the ablated site during follow-up. In two patients with local recurrence at the ablated site, the tumors were in the proximity of major intrahepatic blood vessels. One patient treated with RFA seemed to develop an abscess in the treated area, which led to a false-positive FDG-PET scan. In patients who also underwent resection, the operation did not significantly affect FDG-PET scanning because the area of resection did not provide artifacts on FDG-PET.

Lesion-based posttreatment analysis. In the group of 23 patients, a total of 96 lesions were treated, 56 of them by local ablative therapy. After treatment, 51 lesions became negative on FDG-PET scans, while five lesions still showed activity on FDG-PET scans. In four of five FDG-PET-positive lesions, a local recurrence was detected within 6 months after treatment; one FDG-PET-positive lesion turned out to be an abscess (Table 3). Conversely, none of the FDG-PET-negative lesions developed into a local recurrence during a mean follow-up period of
Coronal FDG-PET

A

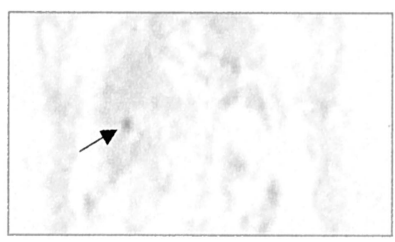

B

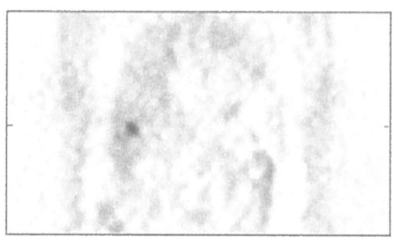

Transverse FDG-PET
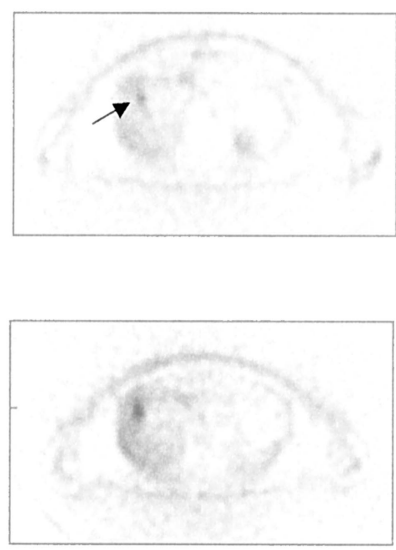

CT
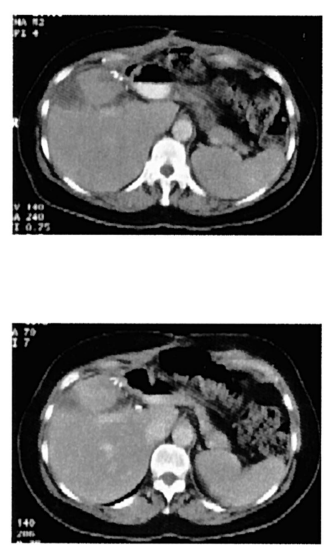

Fig 1. FDG-PET and $C T$ after treatment: (A) after 3 months, (B) 6 months, and (C) 9 months. After 3 months, FDGPET showed clear FDG accumulation, revealing residual disease. Abnormalities on CT after 3 and 6 months were interpreted as posttreatment effects; while tumor recurrence was diagnosed on CT after 9 months.

C

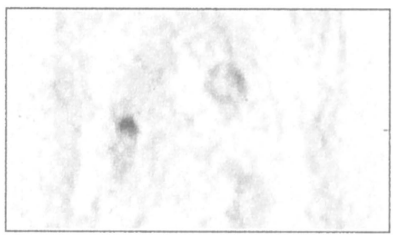

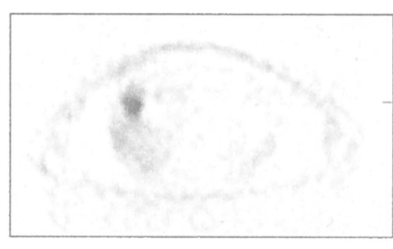

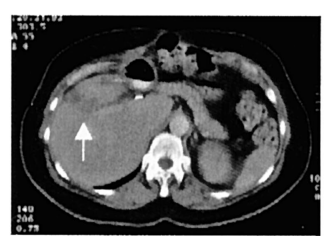

Downloaded from ascopubs.org by Radboud University Nijmegen on December 12, 2019 from 131.174.248.154 Copyright ( $\odot 2019$ American Society of Clinical Oncology. All rights reserved. 
Table 3. Lesion-Based Analysis of FDG-PET and Local Recurrence After Local Tumor Ablation

\begin{tabular}{lcc}
\hline & Recurrence & No Recurrence \\
\hline FDG-PET positive & 4 & 1 \\
FDG-PET negative & 0 & 51 \\
\hline
\end{tabular}

16 months (range, 10 to 21 months). The positive predictive value for the detection of local recurrence in lesions with a positive FDG-PET scan after treatment was $80 \%$; the negative predictive value was $100 \%$.

\section{Imaging During Follow-Up}

Liver. Four patients developed local recurrence at the treated site. As mentioned earlier, in all of these cases initial FDG-PET scans (within 3 weeks after local tumor ablation) showed focal and slightly irregular uptake in the rim of the treated lesion. Unequivocal diagnosis of local recurrence, however, was made when abnormal FDG accumulation typically progressed during follow-up. Therefore, definite diagnosis of local recurrence by FDG-PET was scored after 0.5, 3, 6, and 6 months. On CT scans, these recurrences became apparent several months later, at 4, 9, 9 , and 12 months, respectively. The mean time point of definite detection by FDG-PET was 3.8 months, compared with 8.5 months for CT. One patient proved to have an abscess, which led to a false-positive FDG-PET scan.

Eleven patients developed recurrent disease in the liver outside the treated area during follow-up. All recurrences were detected by FDG-PET as well as by CT. The time of detection, however, varied between FDG-PET and CT. These recurrences were definitely determined by FDG-PET at 3 months $(n=3), 6$ months $(\mathrm{n}=2), 9$ months $(\mathrm{n}=2), 12$ months $(\mathrm{n}=3)$, and 14 months $(\mathrm{n}=1)$ after treatment. On CT scans, these recurrences became apparent several months later, at 6 months $(n=3), 9$ months $(\mathrm{n}=2), 12$ months $(\mathrm{n}=3), 18$ months $(\mathrm{n}=2)$, and 21 months $(\mathrm{n}=1)$. The mean time point of detection by FDG-PET was 8.1 months, compared with 11.7 months for CT (Table 4).

Extrahepatic. Nine patients developed extrahepatic recurrences during follow-up. Two patients had extrahepatic recurrences at multiple sites. In six patients, extrahepatic recurrences were located in the lungs; in one patient, recurrence was located in the abdominal wall; in three patients, extrahepatic metastases were intra-abdominal; and one patient had cerebral metastases (this patient died 10 months after local ablative treatment). Extrahepatic recurrences were definitely determined by FDGPET at 0.5 months $(n=1), 6$ months $(n=3), 9$ months $(n=2)$,
12 months $(\mathrm{n}=2)$, and 15 months $(\mathrm{n}=1)$. In the first patient, the preoperative FDG-PET scan was suspicious but was judged not convincing until progression of the lesion on FDG-PET at 2 weeks after surgery. In one patient, a false-positive outcome was observed because of an extrahepatic abscess. On CT scans, extrahepatic tumor lesions became apparent several months later, at 3 months $(\mathrm{n}=1), 6$ months $(\mathrm{n}=1), 9$ months $(\mathrm{n}=3), 12$ months $(\mathrm{n}=2)$, and 18 months $(\mathrm{n}=1)$. Furthermore, in one patient pulmonary metastases were initially missed on the CT scan, while the FDG-PET scan showed obvious multiple pulmonary metastases; however, these metastases could be seen on the CT scan in retrospect. The mean time point of detection of extrahepatic recurrence by FDG-PET was 8.4 months, compared with 9.8 months for CT.

\section{CEA Measurements}

CEA seemed not to be a very sensitive indicator for tumor recurrence. Ten patients did not show an elevated CEA level before operation (non-CEA secretors). Only 10 (59\%) of 17 patients who had a recurrence of disease during follow-up showed elevated CEA levels ( $>5 \mathrm{ng} / \mathrm{mL}$ ). Of the seven patients with recurrence and no elevated CEA levels during follow-up, two patients were non-CEA secretors at the time of the operation. The other five patients showed normalized CEA levels after local tumor ablation and did not show any increase of CEA at the time of recurrence (Table 4).

\section{DISCUSSION}

This study shows the potential role of FDG-PET in measuring the efficacy of local tumor ablation as well as the added value of FDG-PET in the detection of tumor recurrence during follow-up. The efficacy of local tumor ablation is an important prognostic factor for patients undergoing these procedures. During the process of local ablation, the destruction process cannot easily be ascertained. Ultrasound monitoring is generally used for initial positioning of the RFA or cryoprobe and to ascertain whether the cryolesion seen as a hypoechoic area or the radiofrequencytreated area seen as a hyperechoic area completely engulfs the tumor. Whether indeed tumor-cell kill occurs within these areas is, however, difficult to confirm. Temperatures reached at the edge of (large) lesions may be inadequate. Furthermore, major blood vessels may serve as "heat sinks" and prevent adequate ablation of immediately adjacent tumor. In large lesions, in which multiple probe insertions are necessary, additional repositioning of the electrode may become obscured because of the hypoechoic/hyperechoic focus appearing around the distal probe

Table 4. Tumor Recurrence During Follow-Up

\begin{tabular}{|c|c|c|c|c|c|c|c|c|}
\hline & $\begin{array}{l}\text { Total No. of } \\
\text { Patients With } \\
\text { Recurrence }\end{array}$ & $\begin{array}{c}\text { Elevated } \\
\text { CEA* }^{*}\end{array}$ & $\begin{array}{c}\text { Mean Time of } \\
\text { Detection of } \\
\text { Recurrence by CEA } \\
\text { (months) }\end{array}$ & $\begin{array}{l}\text { FDG-PET } \\
\text { Positive }\end{array}$ & $\begin{array}{l}\text { Mean Time of } \\
\text { Detection of } \\
\text { Recurrence by PET } \\
\text { (months) }\end{array}$ & $\begin{array}{c}\text { CT } \\
\text { Positive }\end{array}$ & $\begin{array}{l}\text { Mean Time of } \\
\text { Detection of } \\
\text { Recurrence by CT } \\
\text { (months) }\end{array}$ & $\begin{array}{l}\text { Time } \\
\text { Difference in } \\
\text { FDG-PET and } \\
\text { CT Detection } \\
\text { (months) }\end{array}$ \\
\hline Local recurrence & 4 & 2 & 11 & $5 \dagger$ & 3.8 & 4 & 8.5 & 4.7 \\
\hline $\begin{array}{l}\text { Liver recurrence outside } \\
\quad \text { treated area }\end{array}$ & 11 & 7 & 12.3 & 11 & 8.1 & 11 & 11.7 & 3.6 \\
\hline Extrahepatic recurrence & 9 & 5 & 12.6 & $10 \neq$ & 8.4 & $8 \S$ & 9.8 & 1.4 \\
\hline
\end{tabular}

${ }^{*}$ Normal CEA $<5 \mathrm{ng} / \mathrm{mL}$.

†One patient had an abscess at the ablated area in the liver.

キOne patient had an extrahepatic abscess.

§ln one patient only (in retrospect), pulmonary metastases were visable on spiral chest CT scan. 
during the application of thermal energy. Monitoring of treatment efficacy in these situations again is difficult.

PET using FDG has emerged as a promising diagnostic modality in patients with colorectal liver metastases. Unlike conventional diagnostic modalities, such as CT scans and ultrasound, which require anatomic alterations for detection of malignancy, FDG-PET provides information on tumor growth based on increased glucose uptake and metabolism of malignant cells.

In this study, 51 lesions became FDG-PET negative directly after local ablative therapy, meaning that FDG-accumulating liver metastases became photopenic. Five lesions remained FDG-PET positive. In four of five FDG-PET-positive lesions, a local recurrence was detected within a mean follow-up period of 16 months; one FDG-PET-positive lesion was an abscess. Conversely, none of the FDG-PET-negative lesions developed a local recurrence in the liver during follow-up. The positive predictive value for the detection of local recurrence in lesions with a positive FDG-PET scan after treatment was $80 \%$; the negative predictive value was $100 \%$. FDG-PET was able to give accurate information about eventual local recurrences at a significantly earlier stage than $\mathrm{CT}$. In the future, this information initially given by FDG-PET should lead to further investigations to collect more precise anatomic information, by CT for example. In this way, FDG-PET determines the need for further investigations and guides the reading of the $\mathrm{CT}$ scan, which on its own is difficult to interpret in the early period after local ablative therapy. This combined information (FDG-PET and CT scans) offers the opportunity to re-treat tumors at an early stage. Although the aims of our study were to investigate the potential role of FDG-PET in determining the efficacy of the local tumor ablative process and to determine the added value of FDG-PET in the detection of tumor recurrence during follow-up, we have performed a second treatment in one patient in whom a lesion remained FDG-PET positive after treatment. At the moment, after our assessment of the value of FDG-PET after local ablative therapy, we now actually do administer a second ablative treatment on any lesions that remain positive.

During further follow-up after local tumor ablation, 11 patients developed recurrent disease in the liver outside the treated area. All recurrences were detected by FDG-PET as well as by CT. The time of detection, however, varied between FDG-PET and CT. The mean time point of detection by FDG-PET was 8.1 months, compared with 11.7 months with CT. In two patients, a surgical reintervention was performed; in the other nine patients, chemotherapy was started.

In cases of extrahepatic tumor recurrence, FDG-PET also seemed to be a sensitive modality. In all nine patients who developed extrahepatic recurrence, FDG-PET scans were positive; in one patient, a false-positive outcome was observed because of an extrahepatic abscess. One extrahepatic recurrence (pulmonary metastases) was initially missed on the CT scan but detected by FDG-PET. In retrospect, these pulmonary metastases could be seen on the CT scan. The mean time point of detection of extrahepatic recurrence by FDG-PET was 8.4 months, compared with 9.8 months for CT. Two patients with pulmonary metastases underwent resection during follow-up. The other patients received chemotherapy.

Thus, in addition to the predictive value of immediate FDGPET in the detection of local tumor recurrence in the liver after tumor ablation, there may also be a role for FDG-PET during further follow-up. Recurrences of disease outside the local ablated area are also detected earlier by FDG-PET than by CT. In our series, four patients underwent surgical reintervention after the detection of recurrent disease outside the local ablated area.

Since FDG is not a tumor-specific substance, an inflammatory process also accumulates the tracer due to increased metabolic activity of leukocytes and macrophages. This is the major well-known source of false-positive FDG-PET results. We also observed two false-positive FDG-PET results, once due to abscess formation in the treated area of the liver and once due to an extrahepatic abscess in the abdomen. These two false-positive FDG-PET readings did not result in a treatment alteration, because FDG-PET was not considered the decisive modality during this study. Postponing the FDG-PET study in case of evidence of active focal infection may prevent false-positive FDG-PET readings. Another limitation of FDG-PET is the limited spatial resolution, which may lead to false-negative reports when the lesions are small $(<1 \mathrm{~cm})$. False-negative results may also occur because of an increased fasting blood glucose level or manifest diabetes mellitus. In some studies, patients with diabetes were therefore excluded. Two of the patients in this study had diabetes mellitus. No false-negative results were observed in these patients during follow-up. However, blood glucose levels were always checked as we were aware of this potential source of error.

For over a decade it has been recognized that PET can be used to detect recurrences from colorectal cancer after FDG administration. ${ }^{19}$ With regard to extrahepatic recurrence, some studies even demonstrate that FDG-PET is more sensitive than conventional cross-sectional imaging methods. ${ }^{20,21}$ Delbeke et $\mathrm{al}^{22}$ found in a series of 52 patients with recurrent colorectal cancer that FDG-PET was more accurate than CT for the detection of extrahepatic disease $\left(92 \% \vee 71 \%\right.$, respectively). Fong et $\mathrm{al}^{23}$ showed unexpected extrahepatic disease detected by FDG-PET in 10 of 40 patients. This finding was confirmed by others. ${ }^{24,25}$ We showed in a recent prospective study that FDG-PET led to clinically relevant extrahepatic findings different from those found with conventional imaging in nine of 51 patients analyzed for hepatic resection of colorectal liver metastases. In this study, FDG-PET findings led to a change in clinical management in $20 \%$ of patients. ${ }^{26}$ In the present study, we confirm our earlier observation and show furthermore that FDG-PET reveals extrahepatic recurrences earlier than CT.

For the detection of liver metastases, however, the value of FDG-PET has not been fully determined. Spiral CT is currently regarded as the best method for evaluating the anatomy and resectability of colorectal liver metastases. The extent of liver involvement and the relationship of the metastases to the biliary and vascular structures generally determine resectability of liver metastases. Therefore, given the limited anatomic information provided at this stage by FDG-PET, FDG-PET by itself will not become a substitute for the anatomic imaging provided by CT. With regard to sensitivity of tumor detection, however, several authors have reported a higher accuracy for FDG-PET compared with spiral CT. In a series by Vitola et $a l,{ }^{27}$ the sensitivity for the detection of liver metastases by FDG-PET and CT was 93\% and $76 \%$, respectively. In a study by Hustinx et $\mathrm{al}^{28}{ }^{28}$ the values were $92 \%$ and $85 \%$, respectively. However, sensitivity of FDG-PET for colorectal liver metastases is considered to be directly related to tumor size, as described by Fong et al. ${ }^{23}$ They found that in Nijmegen on December 12, 2019 from 131.174.248.154 Clinical Oncology. All rights reserved. 
lesions less than $1 \mathrm{~cm}$ the sensitivity of FDG-PET decreased considerably to $21 \%$. Surprisingly, our current study shows an early detection of liver recurrence, so FDG-PET was able to detect recurrences even when the lesions were small. An explanation may be the relatively high contrast of FDG-accumulating tumor remnants as compared with the photopenic background of the CSA and RFA lesions, which facilitate identification of pathologic uptake.

In this study, we routinely performed two-phase CT, as is generally recommended in the follow-up of patients after RFA of colorectal liver metastases. ${ }^{29}$ This is in contrast to treatment of patients with suspected recurrence of hepatocellular carcinoma after local tumor ablation. For hepatocellular carcinoma, threephase $\mathrm{CT}$ is recommended because recurrence is best depicted in the early arterial phase. ${ }^{30}$ As stated by Chopra et al, ${ }^{31}$ however, arterial phase images are not recommended in patients with colorectal liver metastases after radiofrequency because they do not provide any additional information.

In our series, local recurrence after local tumor ablation was observed in $17 \%$ of the patients during a follow-up period of at least 16 months. Lesion-based analysis showed a local recur- rence rate of $7 \%$ after local tumor ablation. This value for local recurrence is low in comparison with a local recurrence rate of $44 \%$ described by Adam et al. ${ }^{15}$ Others, however, have also reported local recurrence rates on a lesion basis as low as $2.5 \%$ to $9 \% .^{14,32}$

In conclusion, it seems that FDG-PET performed early after treatment provides additional information about the efficacy of local tumor ablation by differentiating posttreatment changes from residual or recurrent malignant tumor. This study also provides evidence that FDG-PET has an added value in the detection of tumor recurrence during follow-up. FDG-PET reveals hepatic recurrences in or outside the treated area as well as extrahepatic recurrences earlier than conventional follow-up, ie, CT and CEA measurement.

The present study suggests that FDG-PET may become the primary diagnostic tool to detect local recurrence after CSA or RFA, guiding the determination of whether other imaging techniques are needed (in case of a positive FDG-PET scan). However, larger studies are needed to define the precise impact of FDG-PET as a follow-up measure after local ablative therapy.

\section{REFERENCES}

1. Fong Y, Cohen AM, Fortner JG, et al: Liver resection for colorectal metastases. J Clin Oncol 15:938-946, 1997

2. Doci R, Gennari L, Bignami P, et al: One hundred patients with hepatic metastases from colorectal cancer treated by resection: Analysis of prognostic determinants. Br J Surg 78:797-801, 1991

3. Rosen CB, Nagorney DM, Taswell HF, et al: Perioperative blood transfusion and determinants of survival after liver resection for metastatic colorectal carcinoma. Ann Surg 216:493-504, 1992

4. Gayowski TJ, Iwatsuki S, Madariaga JR, et al: Experience in hepatic resection for metastatic colorectal cancer: Analysis of clinical and pathologic risk factors. Surgery 116:703-710, 1994

5. Scheele J, Stangl R, Altendorf-Hofmann A: Hepatic metastases from colorectal carcinoma: Impact of surgical resection on the natural history. Br J Surg 77:1241-1246, 1990

6. Wanebo HJ, Chu QD, Vezeridis MP, et al: Patient selection for hepatic resection of colorectal metastases. Arch Surg 131:322-329, 1996

7. Seifert JK, Junginger T, Morris DL: A collective review of the world literature on hepatic cryotherapy. J R Coll Surg Edinb 43:141-154, 1998

8. Bilchik AJ, Wood TF, Allegra DP: Radiofrequency ablation of unresectable hepatic malignancies: Lessons learned. Oncologist 6:24-33, 2001

9. Wood TF, Rose DM, Chung M, et al: Radiofrequency ablation of 231 unresectable hepatic tumors: Indications, limitations, and complications. Ann Surg Oncol 7:593-600, 2000

10. Ruers TJ, Jager GJ, Wobbes T: Cryosurgery for colorectal liver metastases. Semin Oncol 27:120-125, 2000 (suppl 10)

11. Elias D, Cavalcanti A, Sabourin JC, et al: Resection of liver metastases from colorectal cancer: The real impact of the surgical margin. Eur J Surg Cancer 24:174-179, 1998

12. Solbiati L, Ierace $\mathrm{T}$, Tonolini $\mathrm{M}$, et al: Radiofrequency thermal ablation of hepatic metastases. Eur J Ultrasound 13:149-158, 2001

13. Curley SA, Izzo F, Delrio P, et al: Radiofrequency ablation of unresectable primary and metastatic hepatic malignancies: Results in 123 patients. Ann Surg 230:1-8, 1999

14. Crews KA, Kuhn JA, McCarty TM, et al: Cryosurgical ablation of hepatic tumors. Am J Surg 174:614-617, 1997

15. Adam R, Akpinar E, Johann M, et al: Place of cryosurgery in the treatment of malignant liver tumors. Ann Surg 225:39-38, 1997

16. Rossi S, Di Stasi M, Buscarini E, et al: Percutaneous RF interstitial thermal ablation in the treatment of hepatic cancer. AJR Am J Roentgenol 167:759-768, 1996

17. Ruers TJ, Joosten J, Jager GJ, et al: Long-term results of treating hepatic colorectal metastases with cryosurgery. Br J Surg 88:844-849, 2001
18. Goldberg SN, Gazelle GS, Mueller PR: Thermal ablation therapy for focal malignancy: A unified approach to underlying principles, techniques, and diagnostic imaging guidance. AJR Am J Roentgenol 174:323-331, 2000

19. Yonekura Y, Benua RS, Brill AB, et al: Increased accumulation of 2-deoxy-2-[18F]fluoro-D-glucose in liver metastases from colon carcinoma. J Nucl Med 23:1133-1137, 1982

20. Flanagan FL, Dehdashti F, Ogunbiyi OA, et al: Utility of FDG-PET for investigating unexplained plasma CEA elevation in patients with colorectal cancer. Ann Surg 227:319-323, 1998

21. Vitola JV, Delbeke D, Meranze SG, et al: Positron emission tomography with F-18-fluorodeoxyglucose to evaluate the results of hepatic chemoembolization. Cancer 78:2216-2222, 1996

22. Delbeke D, Vitola JV, Sandler MP, et al: Staging recurrent metastatic colorectal carcinoma with PET. J Nucl Med 38:1196-1201, 1997

23. Fong Y, Saldinger PF, Akhurst T, et al: Utility of $18 \mathrm{~F}-\mathrm{FDG}$ positron emission tomography scanning on selection of patients for resection of hepatic colorectal metastases. Am J Surg 178:282-287, 1999

24. Lai DT, Fulham M, Stephen MS, et al: The role of whole-body positron emission tomography with $[18 \mathrm{~F}]$ fluorodeoxyglucose in identifying operable colorectal cancer metastases to the liver. Arch Surg 131:703-707, 1996

25. Staib L, Schirrmeister H, Reske SN, et al: Is (18)F-fluorodeoxyglucose positron emission tomography in recurrent colorectal cancer a contribution to surgical decision making? Am J Surg 180:1-5, 2000

26. Ruers TJ, Langenhoff BS, Neeleman N, et al: The value of positron emission tomography with [F-18] fluorodeoxyglucose in patients with colorectal liver metastases: A prospective study. J Clin Oncol 15:388-395, 2002

27. Vitola JV, Delbeke D, Sandler MP, et al: Positron emission tomography to stage suspected metastatic colorectal carcinoma to the liver. Am J Surg 171:21-26, 1996

28. Hustinx R, Paulus P, Jacquet N, et al: Clinical evaluation of whole-body $18 \mathrm{~F}$-fluorodeoxyglucose positron emission tomography in the detection of liver metastases. Ann Oncol 9:397-401, 1998

29. McGahan JP, Dodd GD: Radiofrequency ablation of the liver: Current status. AJR Am J Roentgenol 176:3-16, 2001

30. Catalano O, Lobianco R, Esposito M, et al: Hepatocellular carcinoma recurrence after percutaneous ablation therapy: Helical CT patterns. Abdom Imaging 26:375-383, 2001

31. Chopra S, Dodd GD, Chintapalli KN, et al: Tumor recurrence after radiofrequency thermal ablation of hepatic tumors: Spectrum of findings on dual-phase contrast-enhanced CT. AJR Am J Roentgenol 177:381-387, 2001

32. Ravikumar TS, Kane R, Cady B, et al: A 5-year study of cryosurgery in the treatment of liver tumors. Arch Surg 126:1520-1523, 1991 


\section{Journal of Clinical Oncology}

The Official Journal of the American Society of Clinical Oncology

\section{EDITORIAL}

Autologous Stem-Cell Transplantation as a Component of Initial Treatment for Poor-Risk Patients With Aggressive Non-Hodgkin's Lymphoma: Resolved Issues Versus Remaining Opportunity

Richard I. Fisher

\section{ORIGINAL REPORTS}

\section{Hematologic Malignancies}

Randomized Study to Evaluate the Use of High-Dose Therapy as Part of Primary Treatment for

"Aggressive" Lymphoma Ulrich Kaiser, Irmgard Uebelacker, Ulrich Abel, Josef Birkmann, Lorenz Trümper, Harald Schmalenberg, Tunca Karakas, Bernd Metzner, Dieter K. Hossfeld, Helge G. Bischoff, Astrid Franke, Marcel Reiser, Peter Müller, Luisa Mantovani, Marc Grundeis, Frank Rothmann, Cay-Uwe von Seydewitz, Rolf M. Mesters, Ernst U. Steinhauer, Dorothea Krahl, Kurt Schumacher, Michael Kneba, Michael Baudis, Norbert Schmitz, Rüdiger Pfab, Hubert Köppler, Reza Parwaresch, Michael Pfreundschuh, and Klaus Havemann

(U) Phase I Trial of the Proteasome Inhibitor PS-341 in Patients With Refractory Hematologic Malignancies Robert Z. Orlowski, Thomas E. Stinchcombe, Beverly S. Mitchell, Thomas C. Shea, Albert S. Baldwin, Stephanie Stahl, Julian Adams, Dixie-Lee Esseltine, Peter J. Elliott, Christine S. Pien, Roberto Guerciolini, Jessica K. Anderson, Natalie D. Depcik-Smith, Rita Bhagat, Mary Jo Lehman, Steven C. Novick, Owen A. O'Connor, and Steven L. Soignet

Pediatric Oncology

(U) Children From Ethnic Minorities Have Benefited Equally as Other Children From Contemporary Therapy for Rhabdomyosarcoma: A Report From the Intergroup Rhabdomyosarcoma Study Group K. Scott Baker, James R. Anderson, Thom E. Lobe, Moody D. Wharam, Stephen J. Qualman, R. Beverly Raney, Frederick B. Ruymann, Richard B. Womer, William H. Meyer, Michael P. Link, and William M. Crist

\footnotetext{
Journal of Clinical Oncology (ISSN 0732-183X) is published 24 times a year, twice monthly, by Lippincott Williams \& Wilkins, 351 West Camden Street, Baltimore, MD 21201-2436. Periodicals postage paid at Hagerstown, MD, and at additional mailing offices. The GST number for Canadian Subscribers is 895524239 .

Editorial correspondence should be addressed to Daniel G. Haller, MD, Journal of Clinical Oncology, 330 John Carlyle St, Suite 300, Alexandria, VA 22314. Telephone: (703) 797-1900; FAX: (703) 684-8720. Email: jco@asco.org. Internet: http://www.jco.org

POSTMASTER: ASCO members send change of address to American Society of Clinical Oncology, 1900 Duke St, Suite 200, Alexandria, VA 22314. Non-members send change of address to Journal of Clinical Oncology, c/o Lippincott Williams \& Wilkins, PO Box 1550, Hagerstown, MD 21740.

Yearly subscription rates: United States and possessions: individual, $\$ 325.00$; institution, $\$ 452.00$; single issue, $\$ 25.00$. Canada and Mexico: individual, \$456.00; institution, \$583.00; single issue, \$25.00. All other countries: individual, \$496.00; institution, \$623.00; single issue, \$25.00. Student and resident: United States and possessions: \$127.00, Canada and Mexico: \$153.00, all other countries: \$193.00. To receive student/resident rate, orders must be accompanied by name of affiliated institution, date of term, and the signature of program/residency coordinator on institution letterhead. Orders will be billed at individual rate until proof of status is received. Current prices are in effect for back volumes and back issues. Back issues sold in conjunction with a subscription rate are on a prorated basis. Subscriptions are accepted on a calendar year basis. Prices are subject to change without notice. Single issues, both current and back, exist in limited quantities and are offered for sale subject to availability. Publication Mail Agreement Number 863289.
} 
(U) Prospective, Randomized, Double-Blind, Placebo-Controlled Trial of Marimastat After Response to FirstLine Chemotherapy in Patients With Small-Cell Lung Cancer: A Trial of the National Cancer Institute of Canada-Clinical Trials Group and the European Organization for Research and Treatment of Cancer ......... Frances A. Shepherd, Giuseppe Giaccone, Lesley Seymour, Channa Debruyne, Andrea Bezjak, Vera Hirsh, Michael Smylie, Sheldon Rubin, Heidi Martins, Alan Lamont, Maciej Krzakowski, Anna Sadura, and Benny Zee

Safety and Pharmacokinetic Effects of TNP-470, an Angiogenesis Inhibitor, Combined With Paclitaxel in

Patients With Solid Tumors: Evidence for Activity in Non-Small-Cell Lung Cancer ....... Roy S. Herbst, Timothy L. Madden, Hai T. Tran, George R. Blumenschein, Jr, Christina A. Meyers, Lee F. Seabrooke, Fadlo R. Khuri, Vinay K. Puduvalli, Victoria Allgood, Herbert A. Fritsche, Jr, Leslie Hinton, Robert A. Newman, Elizabeth A. Crane, Frank V. Fossella, Margaret Dordal, Thomas Goodin, and Waun Ki Hong

Genitourinary Cancer

Prognostic Factors for Relapse in Stage I Seminoma Managed by Surveillance: A Pooled Analysis Padraig Warde, Lena Specht, Alan Horwich, Tim Oliver, Tony Panzarella, Mary Gospodarowicz, and Hans von der Maase

\section{Gastrointestinal Cancer}

Efficacy of Fluorine-18-Deoxyglucose Positron Emission Tomography in Detecting Tumor Recurrence After Local Ablative Therapy for Liver Metastases: A Prospective Study B.S. Langenhoff, W.J.G. Oyen, G.J. Jager, S.P. Strijk, Th. Wobbes, F.H.M. Corstens, and T.J.M. Ruers

Therapeutic Efficacy of Transcatheter Arterial Chemoembolization as Compared With Hepatic Resection in Hepatocellular Carcinoma Patients With Compensated Liver Function in a Hepatitis B Virus-Endemic Area: A Prospective Cohort Study .......... Hyo-Suk Lee, Kang Mo Kim, Jung-Hwan Yoon,
Tae-Rim Lee, Kyung Suk Suh, Kuhn Uk Lee, Jin Wook Chung, Jae Hyung Park, and Chung Yong Kim

Sarcoma

(U) Efficacy and Safety of Carbon Ion Radiotherapy in Bone and Soft Tissue Sarcomas Tadashi Kamada, Hirohiko Tsujii, Hiroshi Tsuji, Tsuyoshi Yanagi, Jun-etsu Mizoe, Tadaaki Miyamoto, Hirotoshi Kato, Shigeru Yamada, Shinroku Morita, Kyousan Yoshikawa, Susumu Kandatsu, and Akio Tateishi for the Working Group for the Bone and Soft Tissue Sarcomas

Function and Health Status Outcomes in a Randomized Trial Comparing Preoperative and Postoperative

Radiotherapy in Extremity Soft Tissue Sarcoma ........... A.M. Davis, B. O'Sullivan, R.S. Bell, R. Turcotte, C.N. Catton, J.S. Wunder, P. Chabot, A. Hammond, V. Benk, M. Isler, C. Freeman, K. Goddard, A. Bezjak, R.A. Kandel, A. Sadura, A. Day, K. James, D. Tu, J. Pater, and B. Zee

Clinical Trials

Randomized Discontinuation Design: Application to Cytostatic Antineoplastic Agents Gary L. Rosner, Walter Stadler, and Mark J. Ratain

Genetic Testing for Cancer

BRCA1/2 Genetic Testing in the Community Setting Wendy Y. Chen, Judy E. Garber, Suzanne Higham, Katherine A. Schneider, Katie B. Davis, Amie M. Deffenbaugh, Thomas S. Frank, Rebecca S. Gelman, and Frederick P. Li 


\title{
REVIEW ARTICLE
}

Limb Salvage and Amputation in Survivors of Pediatric Lower-Extremity Bone Tumors: What Are the Long-Term Implications? Rajaram Nagarajan, Joseph P. Neglia,

\section{SPECIAL DEPARTMENTS}

\author{
Announcements \\ Current Abstracts \\ Books Received \\ Internet Access \\ JCO Homepage \\ ASCO OnLine .
}

Information for Contributors

(U) Online supplementary information Available at http://www.jco.org

$\star$ Article was published online ahead of print at $h t t p: / / w w w . j c o . o r g$ 